\title{
The quality of preventive health care delivered to adults: results from a cross-sectional study in Southern Italy
}

\author{
Benedetto Manuti, Paolo Rizza, Aida Bianco*, Carmelo GA Nobile, Maria Pavia
}

\begin{abstract}
Background: It is assumed that providing clinical preventive services to patients can identify or detect early important causes of adult mortality. The aim of this study was to quantify access to preventive services in Southern Italy and to assess whether and how the provision of preventive care was influenced by any specific characteristics of patients.

Methods: In a cross-sectional study adults aged 18 years and over attending primary care physician (PCP) offices located in Southern Italy were interviewed from June through December 2007. Quality indicators of preventive health care developed from RAND's Quality Assessment Tools and Behavioral Risk Factor Surveillance System (BRFSS) were used. Multivariate analysis was performed to identify and to assess the role of patients' characteristics on delivery of clinical preventive services.

Results: A total of 1467 subjects participated in the study. Excepting blood pressure preventive check (delivered to $64.4 \%$ of eligible subjects) and influenza vaccination (recommended to $90.2 \%$ of elderly), the rates of delivery of clinical preventive services were low across all measures, particularly for screening and counseling on health habits. Rates for providing cancer screening tests at recommended times were $21.3 \%$ for colonoscopy, 51.5\% for mammography and $52.4 \%$ for Pap smear. Statistical analysis showed clear disparities in the provision of clinical preventive services associated with age, gender, education level, perceived health status, current health conditions and primary care access measures.
\end{abstract}

Conclusions: There is overwhelming need to develop and implement effective interventions to improve delivery of routine clinical preventive services.

\section{Background}

Scientific consensus holds that the provision of clinical preventive services to adults can identify and detect many causes of adult mortality. Despite the fact that prevention is a core component of primary care practice, there is widespread evidence that clinical preventive service delivery rates are low and generally sub-optimal [1].

To assess the extent to which the healthcare system succeeds in providing essential clinical preventive services, composite measures have been developed. Among these measures, the RAND's Quality Assessment Tools system has been extensively used to assess the quality of

\footnotetext{
* Correspondence: a.bianco@unicz.it
Chair of Hygiene, Medical School, University of Catanzaro "Magna Græcia",

* Correspondence: a.bianco@unicz.it
Chair of Hygiene, Medical School, University of Catanzaro "Magna Græcia", Catanzaro, Italy
}

(c) 2010 Manuti et al; licensee BioMed Central Ltd. This is an Open Access article distributed under the terms of the Creative Commons Attribution License (http://creativecommons.org/licenses/by/2.0), which permits unrestricted use, distribution, and reproduction in any medium, provided the original work is properly cited.

certain preventive services which are routinely recommended for adults regarding screening and counseling on health habits, physical examination, vaccinations and screening for cancers [2]. Previous studies in USA have found significant disparities in the provision of these clinical preventive services, and these disparities are associated with the patients' characteristics, such as sex, age, race or ethnic group, income and health insurance [3-6].

In Italy, where universal and free access to interventions included in the Basic Healthcare Parameters is provided through the National Health Service (NHS), financial resources for prevention are very limited; furthermore, preventive healthcare that is provided by Prevention Departments and primary care physicians (PCPs), is often not properly organized. Moreover, 
during the 1990s the Italian NHS was decentralized into twenty independent regions, thus increasing the risk of inequality in access to health in the more impoverished places of the South. Indeed, studies have demonstrated a striking imbalance in the provision of preventive health services, especially in breast, cervical and colorectal cancer screening, with higher coverage always in Northern and Central Italy compared to Southern Italy, where organised systematic screening activity has not yet been completely implemented [7-9].

Several studies have been published which focused on a narrow set of quality indicators and conditions in selected populations, but they showed limited ability to evaluate the role of specific factors associated with poorer quality [10-12]. Very few studies have examined the quality of preventive care for multiple conditions [13-16]. In the present study, we intend to quantify the access to various preventive services in Southern Italy, and to identify the relationships between patients' characteristics and the quality of preventive care which is supplied by PCPs.

\section{Methods}

\section{Study population}

A cross-sectional study was conducted at waiting rooms of 20 PCPs in two cities of Southern Italy (Catanzaro and Crotone), randomly selected from lists provided by the Local Health Units. Catanzaro had 60 PCPs and Crotone 38. These two cities, Catanzaro and Crotone, are located in the Calabria Region (2 million inhabitants as a whole) in the extreme southeastern part of Italy; the former is the capital of the region and the latter is a small town, yet they have common urban and demographic characteristics typical of the southern region of the country. The adult population was 77,022 in Catanzaro and 44,047 in Crotone. From June through December 2007 two trained physicians gathered information from adult patients attending PCPs who consented to participate, to determine "technical process quality" (whether or not patients were offered recommended services for which they were eligible) across a wide spectrum of preventive healthcare services. On average, 30 patients were attending consultations on each occasion. All information was self-reported by the participants. No medical records or interviews by any PCPs were used as sources of data.

Sample size calculation assumed the worst scenario of an estimated proportion of each characteristic of interest in $50 \%$ of the population. As we were interested in at least 200 subjects in each subgroup within the sample for each separate estimate required, we decided to be conservative and to increase our sample size to 1500 subjects so that we would have sufficient precision in the estimates on the whole sample.

\section{Review instrument}

The RAND Quality Assessment Tools system is a composite of 35 quality indicators, of which we selected 15 [2]: to assess potential problems with underuse of the following preventive services routinely recommended for adults: screening and counseling on health habits (sexual activity, drug abuse, alcohol consumption and smoking cessation), physical examination (blood pressure check and evaluation of hearing difficulties), vaccinations against influenza and pneumococcal disease (in all patients $65 \mathrm{yrs}$ and over and in patients younger than 65 yrs with conditions that represent a risk for severe complications in subjects undergoing influenza and pneumococcal disease) and recommended screening for early diagnosis of cancers according to age and gender (breast, cervical and colorectal). (See Additional file 1). The decision to exclude 20 indicators was suggested for several reasons:

1) we excluded 11 indicators because they needed to be verified by medical records; 2) we excluded 8 indicators that pertained to subgroups of populations that would be rarely encountered in our setting and would therefore offer low numbers of eligible subjects (for example, pregnant women not immune to rubella or women with a history of cervical dysplasia or carcinoma-in-situ or HIV infection who have not had Pap smear within the past year ); 3) we excluded one indicator that predictably would have an absolute $100 \%$ failure rate (that is, counseling regarding the use of seat belts).

We defined chronic diseases (using WHO criteria) as diseases of long duration and generally slow progression, such as heart disease, stroke, cancer, chronic respiratory diseases, diabetes etc. [17], and we classified participants as having chronic diseases if they reported ever being advised by a healthcare worker that they had a chronic disease and/or if they were currently in treatment for these conditions. Similarly, we defined participants as hypertensive if they reported ever being advised by a healthcare worker that they had high blood pressure and/or if they were taking an antihypertensive medication.

Additional questions were derived from the BRFSS 2007 Questionnaire [18]. These evaluated smoking and alcohol consumption habits, as well as recommendations of physicians on how to reduce behavioral risk factors related to high blood pressure, and on compliance of patients to colorectal, breast and cervix cancer screening. We defined current smokers as people who reported smoking at least 100 cigarettes during their lifetime and who currently smoke every day or some days. Current drinking was defined as consuming alcohol on one or more of the previous 30 days. Heavy drinking was defined as an average consumption of more than 2 drinks per day during the previous 30 days 
among men and more than 1 drink per day during the previous 30 days among women ( $>30$ drinks/month). Excessive alcohol use was defined on the basis of either heavy drinking (high average consumption), binge drinking (high per occasion consumption), or both [19].

The interview was also intended to collect the following data for each patient: socio-demographics (age, sex, marital status, number of persons in the household, education level, working activity), perception of health status and utilization of health services during the previous year (specialist visits, emergency accesses, and hospital admissions).

We used level of education as a proxy indicator for socioeconomic status (SES) for several reasons, such as ease of measurement, applicability to persons not in the active labor force (e.g. homemakers, unemployed, and retired), and stability over adult lifespan. We preferred this definition instead of measuring income, since subjects consider this information too sensitive, and as a result they may offer less truthful responses. The perception of health status was assessed by using two components, 12-Physical Component Summary (PCS-12) and 12-Mental Component Summary (MCS-12), from the Medical Outcomes Study's 12-Item Short-Form Survey Instrument, $S F-12$, in its validated Italian version [20-22].

The study protocol was approved by Ethics Committee of the "Mater Domini" Hospital of Catanzaro (Italy) (Prot. E.C. n. 127/2006).

\section{Statistical analysis}

Multivariate stepwise logistic regression analysis was performed. Six models were developed including those variables potentially associated with the following outcomes of interest: blood pressure check on all patients otherwise presenting for care at least once each year (Model 1) $(0=$ no, $1=$ yes); colorectal cancer screening with sigmoidoscopy or colonoscopy within the previous 10 years received by subjects aged 50 to 80 (Model 2) $(0=$ no, $1=$ yes $)$; cervical cancer screening received within the previous 3 years by all sexually active women (Model 3) $(0=$ no, 1 = yes); breast cancer screening received in the previous 2 years by women aged 50 to 70 (Model 4$)(0=$ no, $1=$ yes); influenza and pneumococcal vaccinations offered at recommended times to subjects aged 65 and over (Model 5) $(0=$ no, $1=$ yes); alcohol problem screening received by all subjects (Model 6) $(0=$ no, $1=$ yes). In all models the explanatory variables included were the following: gender (male $=0$, female $=1$ ) when appropriate, age (continuous), marital status (married $=0$, other $=1$ ), additional persons in the household (ordinal: none $=0,1=1,>1=2$ ), education level (ordinal: no formal education $=1$, primary school $=2$, secondary school $=3$, high school or higher $=4$ ), working activity (housewife/student/ unemployed $/$ retired $=1$, other $=2$ ), chronic disease (none $=0, \geq 1=1$ ), PCS score (continuous), MCS score (continuous), current tobacco use (ordinal: not at all = 0 , some days $=1$, every day $=2$ ), excessive alcohol use $($ no $=0$, yes $=1)$, PCP accesses in the previous year $(<1$ time per month $=0, \geq 1$ time per month $=1)$, PCP medical visits in the previous year (ordinal: none $=0,<1$ time per month $=1, \geq 1$ time per month $=2)$, specialist visits in community health services (none $=0, \geq 1=1$ ), private specialist visits (none $=0, \geq 1=1$ ), emergency accesses in the previous year (none $=0, \geq 1=1$ ) and hospital admissions in the previous year (none $=0, \geq 1=$ $1)$. The significance level for variables entering the logistic regression models was set at 0.2 and for removal from the model at 0.4. Adjusted odds ratio (ORs) and 95\% confidence intervals (CIs) were calculated. The data were analyzed using the Stata software program, version 10.1 (Stata Corporation. College Station, TX) [23].

\section{Results}

Of 1716 adults who were eligible for the study, 1467 agreed to participate and were enrolled, for a response rate of $85.5 \%$. The main characteristics of the study population regarding socio-demographic profile, health condition and utilization of health services are presented in Table 1. Of all participants, $50.7 \%$ were current or ex-smokers; current drinkers (with an average of 1.5 drinks) and excessive drinkers were $58.1 \%$ and $8.3 \%$, respectively. The mean score of perceived health status was 45.9 for PCS-12 and 44.9 for MCS-12. Of the participants, $46.7 \%$ had access at least monthly to a PCP, $39.3 \%$ and $47 \%$ had at least one specialist visit to the public or private sector, respectively; $23 \%$ and $12.8 \%$ reported at least one emergency visit and one hospital admission, respectively.

Regarding recommendations of PCPs on specifically reducing behavioral risk factors related to high blood pressure, $97 \%$ of the subjects claimed to have been advised on the use of drugs, almost $90 \%$ in the reduction of salt consumption, more than $80 \%$ in changing eating habits and augmenting physical activity, while fewer than three quarters were advised about reducing alcohol consumption (Table 2).

Tables 2 and 3 show, respectively, the rates of delivery and the relationship between patients' characteristics and access to selected clinical preventive services stratified by multivariate analysis. Providing health habits preventive services was extremely low (less than $20 \%$ ); those participants who were screened for drinking problems (16\%) were significantly more likely to be males, excessive drinkers, less educated and frequent users of health services (PCP' and public specialist' medical visits). Blood pressure check in nonhypertensives showed 
Table 1 Selected characteristics of the study population

\begin{tabular}{|c|c|}
\hline Characteristic & N (\%) \\
\hline \multicolumn{2}{|l|}{ Sex } \\
\hline Male & $660(45)$ \\
\hline Female & $807(55)$ \\
\hline \multicolumn{2}{|l|}{ Age group, years } \\
\hline $18-45$ & $498(33.9)$ \\
\hline $46-64$ & $541(36.9)$ \\
\hline$\geq 65$ & $428(29.2)$ \\
\hline \multicolumn{2}{|l|}{ Education level } \\
\hline No formal education & $305(20.8)$ \\
\hline Primary school & $309(21)$ \\
\hline Secondary school & $588(40.1)$ \\
\hline University degree & $265(18.1)$ \\
\hline \multicolumn{2}{|l|}{ Marital status } \\
\hline Married & $988(67.3)$ \\
\hline Other & $479(32.7)$ \\
\hline \multicolumn{2}{|l|}{ Living condition } \\
\hline With family & $1020(69.5)$ \\
\hline Other & $447(30.5)$ \\
\hline \multicolumn{2}{|c|}{ Additional persons in the household } \\
\hline None & $138(9.4)$ \\
\hline 1 & $384(26.2)$ \\
\hline$>1$ & $945(64.4)$ \\
\hline \multicolumn{2}{|l|}{ Working activity } \\
\hline No & $843(57.5)$ \\
\hline Yes & $624(42.5)$ \\
\hline \multicolumn{2}{|l|}{ Chronic diseases } \\
\hline No & $579(39.5)$ \\
\hline Yes & $888(60.5)$ \\
\hline \multicolumn{2}{|l|}{ Hypertension } \\
\hline No & $972(66.3)$ \\
\hline Yes & $495(33.7)$ \\
\hline \multicolumn{2}{|l|}{ Tobacco use in entire life } \\
\hline No & $724(49.3)$ \\
\hline Yes & $743(50.7)$ \\
\hline \multicolumn{2}{|c|}{ Frequency of current smoking } \\
\hline Not at all & $360(48.4)$ \\
\hline Some day & $37(5)$ \\
\hline Every day & $346(46.6)$ \\
\hline
\end{tabular}

Attempts to quit smoking in entire life among current smokers

$\begin{array}{ll}\text { No } & 184(48) \\ \text { Yes } & 199(52)\end{array}$

Attempts to quit smoking in the previous year among current smokers

$\begin{array}{ll}\text { No } & 109(54.8) \\ \text { Yes } & 90(45.2)\end{array}$

Alcohol consumption in the previous 30 days

$\begin{array}{ll}\text { No } & 615(41.9) \\ \text { Yes } & 852(58.1)\end{array}$

Table 1: Selected characteristics of the study population (Continued)

\begin{tabular}{|c|c|c|}
\hline \multicolumn{3}{|l|}{ Excessive alcohol use } \\
\hline No & $1346(91.7)$ & \\
\hline Yes & $121(8.3)$ & \\
\hline \multicolumn{3}{|l|}{ Perceived health status } \\
\hline $\begin{array}{l}\text { 12-Physical Component Summary } \\
\text { (PCS-12) }\end{array}$ & & $45.9( \pm 10.8)$ \\
\hline $\begin{array}{l}\text { 12-Mental Component Summary } \\
\text { (MCS-12) }\end{array}$ & & $44.9( \pm 11.6)$ \\
\hline \multicolumn{3}{|l|}{$\mathrm{PCP}^{1}$ accesses in the previous year } \\
\hline$<12$ & $782(53.3)$ & \\
\hline$\geq 12$ & $685(46.7)$ & \\
\hline \multicolumn{3}{|l|}{$\begin{array}{l}\mathrm{PCP}^{1} \text { medical visits in the previous } \\
\text { year }\end{array}$} \\
\hline None & $528(36)$ & \\
\hline$<12$ & $590(40.2)$ & \\
\hline$\geq 12$ & $349(23.8)$ & \\
\hline
\end{tabular}

Specialist visits in community health services in the previous year

$\begin{array}{ll}\text { None } & 890(60.7) \\ \geq 1 & 577(39.3)\end{array}$

Private specialist visits in the previous year

$$
\begin{array}{ll}
\text { None } & 778(53) \\
\geq 1 & 689(47)
\end{array}
$$

Emergency accesses in the previous year

$\begin{array}{ll}\text { None } & 1129(77) \\ \geq 1 & 338(23)\end{array}$

Hospital admissions in the previous year
None
$1279(87.2)$
$\geq 1$ $188(12.8)$

${ }^{1} \mathrm{PCP}=$ primary care physician

higher provision of preventive services compared to hearing difficulties in the elderly (64.3\% versus $31.3 \%)$, and it was significantly more likely to be delivered to older subjects, the less educated and frequent users of health services. Rates of cancer screening were low for all types of cancer-approximately $50 \%$ of those eligible received breast or cervical cancer screening-but they were extremely low for colorectal cancer screening (21\%). Even less likely to receive colorectal cancer screening were women, those with higher educational levels, current smokers, and those admitted to hospital; women, those more educated, married, workers, those with chronic disease and frequent users of private specialists were significantly more likely to receive cervical cancer screening, whereas breast cancer screening was significantly more likely delivered to younger women, those having attended PCP and or having been admitted to hospital admissions in the previous year. The recommendation for influenza vaccination was considerably higher compared with pneumococcal (respectively 90.2\% 
Table 2 Preventive health care delivered and actions to control high blood pressure among Italian adults

\begin{tabular}{|c|c|c|c|}
\hline \multirow[t]{2}{*}{ Preventive Indicators } & \multicolumn{3}{|l|}{ Eligible } \\
\hline & Subjects & $\mathbf{N}^{\circ \dagger}$ & Percent* \\
\hline \multicolumn{4}{|l|}{ Screening and counseling on health habits } \\
\hline Having received screening for drinking problems & all subjects & 1467 & 16 \\
\hline Having been asked about drug abuse history & all subjects ${ }^{\S}$ & 1467 & 6.6 \\
\hline Having received smoking cessation counseling visit within 3 months & all smokers identified as attempting to quit & 68 & 19.1 \\
\hline Having received smoking cessation pharmacoterapy & $\begin{array}{l}\text { all smokers attempting to quit who smoke } \\
\text { more than } 10 \text { cigarettes a day }\end{array}$ & 68 & 11.8 \\
\hline Having been asked about sexual activity history & all subjects $\#$ & 1467 & 9.7 \\
\hline \multicolumn{4}{|l|}{ Physical examination } \\
\hline Having received blood pressure control at least once each year & all non hypertensive subjects & 972 & 64.4 \\
\hline Having received evaluation of hearing difficulties at least every 2 years & subjects aged 65 and over & 428 & 31.3 \\
\hline \multicolumn{4}{|l|}{ Cancer screening services } \\
\hline Having received cervical cancer screening through PAP smear within the past 3 years & $\begin{array}{l}\text { all sexually active women having an intact } \\
\text { uterus }\end{array}$ & 733 & 52.4 \\
\hline $\begin{array}{l}\text { Having received PAP smear or colposcopy in low grade lesion within } 6 \text { months of } \\
\text { the initial PAP smear }\end{array}$ & $\begin{array}{l}\text { women having a PAP smear that shows a } \\
\text { low grade lesion }\end{array}$ & 2 & 50 \\
\hline Having received breast cancer screening through mammography in the past 2 years & women aged 50 to 70 & 297 & 51.5 \\
\hline $\begin{array}{l}\text { Having been offered colorectal cancer screening tests (fecal occult blood test once } \\
\text { each year or double contrast barium enema every } 5 \text { years or sigmoidoscopy or } \\
\text { colonoscopy every } 10 \text { years) }\end{array}$ & subjects aged 50 to 80 & 740 & 21.3 \\
\hline $\begin{array}{l}\text { Having received colorectal cancer screening with sigmoidoscopy or colonoscopy } \\
\text { within in the past } 10 \text { years }\end{array}$ & subjects aged 50 to 80 & 740 & 14.2 \\
\hline \multicolumn{4}{|l|}{ Adult immunization } \\
\hline \multirow[t]{2}{*}{ Having been offered influenza vaccination annually } & subjects aged 65 and over & 428 & 90.2 \\
\hline & patients with specific conditions at risk & 166 & 64.5 \\
\hline \multirow[t]{2}{*}{ Having ever been offered pneumococcal vaccination } & subjects aged 65 and over & 428 & 26.2 \\
\hline & patients with specific conditions at risk & 166 & 19.3 \\
\hline \multicolumn{4}{|c|}{ The advice of doctor or other health professional to help lower or control high blood pressure } \\
\hline Having received advice to Change eating habits & hypertensive subjects & 495 & 84 \\
\hline Having received advice to Reduce salt use & hypertensive subjects & 495 & 89.5 \\
\hline Having received advice to Increase physical activity & hypertensive subjects & 495 & 83.4 \\
\hline Having received advice to Reduce alcohol use & hypertensive subjects & 495 & 73.9 \\
\hline Having received advice to Medication & hypertensive subjects & 495 & 97 \\
\hline
\end{tabular}

${ }^{\dagger}$ Subjects in the study who were eligible for the indicator; * Percent of eligible subjects who have received the recommended preventive services; ${ }^{\S} 1079$ subjects have answered to the question; ${ }^{\#} 1073$ subjects have answered to the question

versus $26.2 \%$ in the elderly, and $64.5 \%$ versus $19.3 \%$ in subjects with conditions at risk for severe complications); older patients with worse perceived physical health status were significantly more likely to benefit from both vaccines.

\section{Discussion}

In this study, among a representative sample of PCP' patients residing in Southern Italy, we had two original intentions: to examine the extent to which the healthcare system succeeds in providing clinical preventive services routinely recommended to adults [24-26] and to explore the disparities in their provision with relation to the patients' characteristics.

This study clearly demonstrates that the quality of preventive care in the target population falls far short of expectations; indeed, access to preventive health services is unsatisfactory even for interventions whose effectiveness is supported by broadly accepted scientific evidence, such as the commonly recommended cancer screening [27-35]. Consistent with other studies conducted in Italy [7-9,36], we found that cancer screening for early detection of breast and cervical cancers reached about half of target population but only one-fifth for colorectal cancer; these rates are discernibly much lower than those results reported in several studies conducted, particularly in the United States, that have shown variable results ranging from $58 \%$ to $89 \%$ for breast cancer, from $69 \%$ to $89 \%$ for cervical cancer, and from $31 \%$ to $57 \%$ for colorectal cancer [3-5,37-42]. Our results however were similar to those reported in studies conducted in vulnerable populations, such as the poor or uninsured or unenrolled in both Medicare and Medicaid programs [43-45], minority patients $[46,47]$ and subjects who lack 
Table 3 Logistic regression models results

\begin{tabular}{|c|c|c|c|c|c|c|}
\hline & Model 1 & Model 2 & Model 3 & Model 4 & Model 5 & Model 6 \\
\hline & $\begin{array}{l}\text { Blood pressure } \\
\text { check }\end{array}$ & $\begin{array}{l}\text { Colorectal cancer } \\
\text { screening }\end{array}$ & $\begin{array}{l}\text { Cervical cancer } \\
\text { screening }\end{array}$ & $\begin{array}{l}\text { Breast cancer } \\
\text { screening }\end{array}$ & $\begin{array}{l}\text { Influenza and } \\
\text { pneumococcal } \\
\text { vaccination }\end{array}$ & $\begin{array}{l}\text { Screening for } \\
\text { drinking problems }\end{array}$ \\
\hline & $\begin{array}{l}\text { Log-likelihood= } \\
-538.66, \chi^{2}= \\
188.34, p<0.0001\end{array}$ & $\begin{array}{l}\text { Log-likelihood= } \\
-273.94, \chi^{2}=56.52 \\
p<0.0001\end{array}$ & $\begin{array}{l}\text { Log-likelihood }= \\
-453.03, \chi^{2}= \\
108.43, p<0.0001\end{array}$ & $\begin{array}{l}\text { Log-likelihood= } \\
-188.48, \chi^{2}=34.49 \\
p=0.0001\end{array}$ & $\begin{array}{l}\text { Log-likelihood }= \\
-237.14, \chi^{2}=17.75 \\
p=0.0131\end{array}$ & $\begin{array}{l}\text { Log-likelihood= } \\
-595.20, \chi^{2}= \\
100.52, p<0.0001\end{array}$ \\
\hline & OR & OR & OR & OR & OR & OR \\
\hline & $(95 \% \mathrm{Cl})$ & $(95 \% \mathrm{Cl})$ & $(95 \% \mathrm{Cl})$ & $(95 \% \mathrm{Cl})$ & $(95 \% \mathrm{Cl})$ & $(95 \% \mathrm{Cl})$ \\
\hline Gender & - & & - & - & - & \\
\hline Male* & & 1.00 & & & & 1.00 \\
\hline \multirow[t]{2}{*}{ Female } & & 0.44 & & & & 0.42 \\
\hline & & $(0.27-0.71)$ & & & & $(0.31-0.57)$ \\
\hline \multirow[t]{2}{*}{ Age, continuous } & 1.03 & 1.02 & - & 0.95 & 1.06 & - \\
\hline & $(1.02-1.05)$ & $(0.99-1.05)$ & & $(0.91-1.00)$ & $(1.01-1.10)$ & \\
\hline \multicolumn{7}{|l|}{ Marital Status } \\
\hline Married* & 1.00 & 1.00 & 1.00 & 1.00 & & 1.00 \\
\hline \multirow[t]{2}{*}{ Other } & 0.74 & 0.73 & 0.33 & 0.60 & - & 0.72 \\
\hline & $(0.53-1.02)$ & $(0.40-1.35)$ & $(0.23-0.47)$ & $(0.33-1.09)$ & & $(0.52-1.01)$ \\
\hline \multirow{2}{*}{$\begin{array}{l}\text { Number in } \\
\text { households, ordinal }\end{array}$} & - & - & 1.24 & - & 1.37 & - \\
\hline & & & $(0.94-1.62)$ & & $(0.98-1.92)$ & \\
\hline \multirow{2}{*}{$\begin{array}{l}\text { Education level, } \\
\text { ordinal }^{\#}\end{array}$} & 0.82 & 0.72 & 1.33 & 1.25 & 1.11 & 0.75 \\
\hline & $(0.68-0.99)$ & $(0.56-0.91)$ & $(1.09-1.62)$ & $(0.95-1.63)$ & $(0.88-1.40)$ & $(0.64-0.87)$ \\
\hline Working activity & - & - & & - & - & - \\
\hline $\begin{array}{l}\text { Housewife/ } \\
\text { student/ } \\
\text { unemployed/ } \\
\text { retired* }\end{array}$ & & & 1.00 & & & \\
\hline \multirow[t]{2}{*}{ Other } & & & 1.52 & & & \\
\hline & & & $(1.05-2.21)$ & & & \\
\hline Chronic disease & & - & & - & - & - \\
\hline None* & 1.00 & & 1.00 & & & \\
\hline \multirow[t]{2}{*}{$\geq 1$} & 1.29 & & 1.81 & & & \\
\hline & $(0.91-1.84)$ & & $(1.23-2.67)$ & & & \\
\hline \multirow[t]{2}{*}{ PCS-12, continuous } & 1.02 & 1.02 & 1.01 & - & 0.98 & - \\
\hline & $(1.00-1.04)$ & $(1.00-1.04)$ & $(1.00-1.03)$ & & $(0.95-1.00)$ & \\
\hline \multirow[t]{2}{*}{ MCS-12, continuous } & - & 1.01 & 1.01 & 1.02 & 1.01 & - \\
\hline & & $(0.99-1.03)$ & $(0.99-1.02)$ & $(1.00-1.04)$ & (0.99-1.03) & \\
\hline \multirow{2}{*}{$\begin{array}{l}\text { Current tobacco } \\
\text { use, ordinal }\end{array}$} & - & 0.69 & 1.20 & 1.34 & 1.24 & - \\
\hline & & $(0.49-0.98)$ & $(0.98-1.47)$ & $(0.93-1.92)$ & $(0.84-1.84)$ & \\
\hline $\begin{array}{l}\text { Excessive alcohol } \\
\text { use }\end{array}$ & & - & - & & & \\
\hline $\mathrm{No}^{*}$ & 1.00 & & & 1.00 & 1.00 & 1.00 \\
\hline \multirow[t]{2}{*}{ Yes } & 0.75 & & & 0.25 & 0.50 & 2.19 \\
\hline & $(0.47-1.22)$ & & & $(0.06-1.04)$ & $(0.14-1.80)$ & $(1.37-3.51)$ \\
\hline $\begin{array}{l}\mathrm{PCP}^{\S} \text { accesses in } \\
\text { the previous year }\end{array}$ & & & - & & - & \\
\hline $\begin{array}{l}<1 \text { time per } \\
\text { month* }\end{array}$ & 1.00 & 1.00 & & 1.00 & & 1.00 \\
\hline \multirow{2}{*}{$\begin{array}{l}\geq 1 \text { time per } \\
\text { month }\end{array}$} & 1.60 & 0.72 & & 1.81 & & 1.17 \\
\hline & $(1.08-2.36)$ & $(0.42-1.23)$ & & $(1.07-3.06)$ & & $(0.82-1.68)$ \\
\hline
\end{tabular}


Table 3: Logistic regression models results (Continued)

\begin{tabular}{|c|c|c|c|c|c|c|}
\hline \multirow{2}{*}{$\begin{array}{l}\mathrm{PCP}^{\S} \text { medical visits } \\
\text { in the previous } \\
\text { year, ordinal }^{\dagger}\end{array}$} & 1.74 & 1.32 & 1.11 & - & - & 1.30 \\
\hline & $(1.34-2.25)$ & $(0.95-1.82)$ & $(0.88-1.40)$ & & & $(1.04-1.62)$ \\
\hline \multicolumn{3}{|l|}{$\begin{array}{l}\text { Specialist visits in } \\
\text { community health } \\
\text { services }\end{array}$} & - & - & - & \\
\hline None* & 1.00 & 1.00 & & & & 1.00 \\
\hline \multirow[t]{2}{*}{$\geq 1$} & 1.49 & 1.34 & & & & 1.46 \\
\hline & $(1.07-2.08)$ & $(0.84-2.13)$ & & & & $(1.08-1.98)$ \\
\hline $\begin{array}{l}\text { Private specialist } \\
\text { visits, }\end{array}$ & - & - & & - & - & - \\
\hline \multicolumn{2}{|l|}{ None* } & & 1.00 & & & \\
\hline \multirow[t]{2}{*}{$\geq 1$} & & & 1.37 & & & \\
\hline & & & $(1.00-1.89)$ & & & \\
\hline $\begin{array}{l}\text { Emergency accesses } \\
\text { in the previous } \\
\text { year, }\end{array}$ & - & - & & & - & \\
\hline \multicolumn{2}{|l|}{ None* } & & 1.00 & 1.00 & & 1.00 \\
\hline \multirow[t]{2}{*}{$\geq 1$} & & & 0.76 & 0.74 & & 1.37 \\
\hline & & & $(0.52-1.11)$ & $(0.39-1.38)$ & & $(0.99-1.90)$ \\
\hline \multicolumn{2}{|l|}{$\begin{array}{l}\text { Hospital admissions } \\
\text { in the previous year }\end{array}$} & & - & & - & - \\
\hline None* & 1.00 & 1.00 & & 1.00 & & \\
\hline$\geq 1$ & 1.33 & 2.80 & & 2.71 & & \\
\hline & $(0.79-2.23)$ & $(1.66-4.72)$ & & $(1.14-6.46)$ & & \\
\hline
\end{tabular}

* reference category; ${ }^{\S} \mathrm{PCP}=$ primary care physician; ${ }^{\circ}$ Number in households: (none $=0,1=1,>1=2$ ); ${ }^{\#}$ Education level: $($ no formal education $=1$, primary school $=2$, secondary school $=3$, high school or higher $=4$ );

$\sim$ Current tobacco use: (not at all $=0$, some days $=1$, every day $=2$ ); ${ }^{+}$PCP medical visits in the previous year: (none $=0,<1$ time per month $=1, \geq 1$ time per month = 2)

a regular care provider [48]. Coverage for cancer screening is probably so low due to the lack of an organised screening program in our Southern region; this is confirmed by studies conducted in Italy that have demonstrated an unmistakable imbalance in the provision of breast, cervical and colorectal cancer screening in Southern Italy [7-9].

We found only two clinical preventive services, blood pressure screening and the recommendation of influenza vaccination in subjects aged 65 and over, that showed satisfactory adhesion, reaching rates similar to or higher than most reported studies $[3,36,49,50]$. The high rate for screening of hypertension may correlate with many factors, such as simplicity and availability of blood pressure measurement, commonly performed with a sphygmomanometer, and to the global awareness of the importance of this clinical service not only by the individual physician but also by patients who did state in the interviews, that they often requested a blood pressure measurement.

The high rates of recommendation of influenza vaccination may reflect a positive attitude of PCPs, and are in accordance with findings of a previous study conducted by some of us in the same area, that indicated positive knowledge, attitudes and behaviours on vaccinations in the elderly in a large majority of PCPs [51].

Moreover, with respect to provision for screening and counseling on health habits services, we found that the rates were drastically lower than those reported in several studies conducted in the United States $[3,15,16,52-54]$. Several factors relating to the individual physician or patient may be mentioned as impediments to the provision of these services: lack of opportunity, lack of time due to other health concerns, the physician's negative attitude towards prevention or anticipated patient refusal; in defense, however, patients may not remember being asked about these conditions since they seemed not overly concerned about them.

Consistent with previous studies [43-47,55-59], we found significant disparities in the delivery of clinical preventive services. Primary care access measures, as well as proxies for the propensity to seek or request care, were all directly related to delivery of clinical preventive services, thus proving that more and better access to primary health care increases the likelihood of delivery of clinical preventive services. Therefore, our results strongly confirm the crucial role of PCPs in promoting preventive services, and agrees with 
previous studies conducted by some of us in the same area [60-62].

Regarding subjects' socio-demographic characteristics, in accord with several studies [3,47,55-59], we found that gender and age were related to disparities of delivery of certain clinical preventive services. Elderly men were more likely to have blood pressure checks and recommended routine influenza and pneumococcal vaccinations, but elderly women were less likely to receive mammography than younger women; moreover, females were less likely to have access to screening for drinking problems and to sigmoidoscopy or colonoscopy. The reasons for the observed demographic disparities are complex and vary according to outcomes. For instance, age-difference may be attributable to the awareness that the elderly are more susceptible to flu or pneumococcal disease [51] and hypertension [25], whereas early diagnosis of breast cancer has an attributable best benefit for younger groups [29]. Gender-related differences for screening for drinking problems may relate to perceived differences in alcohol intake between males and females [59] while colon cancer screening may reflect the preference among women to avoid invasive tests [58].

Contrary to expectations, level of education unevenly influenced access to clinical preventive services. A key finding was that women with higher level of education were more likely to have access to Pap smear but less access to colonoscopy and blood pressure check. A previous survey by the National Institute of Statistics (ISTAT) [63], showed that in Italy, particularly in the South, the use of the Pap test is more frequent among women with higher education level. Previous studies also show that disparities in levels of education (and its cognate, health literacy) is directly proportional to disparities in preventive care services [3,47,64-66]. We found, contrary to that, that higher level of education does not lead to a better access to preventive services as a whole, probably because high education level alone is not sufficient to ensure the necessary awareness of the importance of preventive care. In the healthcare system currently instituted in Southern Italy, the more educated the patient the less likely he is to consider the PCP as the central figure to consult when needed and this is confirmed by our results which show that more educated subjects prefer private specialists, and the PCP is consulted mainly for drug prescription[61].

The finding that screening for alcohol problem was significantly associated with alcohol intake is consistent with the results of a recent survey [67], that demonstrated that physicians try to motivate patients to address alcohol problems especially if they are heavy drinkers.

Finally, consistent with the national ISTAT data [68] revealing a distinctive North-South gradient, we found that the PCS-12 and MCS- 12 mean scores were lower than Italian general population norms, with a difference score of -2.7 and -5 , respectively [22]; moreover Wallace et al [69] reports that the low scores are influenced by lack of social support and we may suggest that this sociological factor influences our current results as well. Of some interest, the health summary scores do not correspond significantly with the outcomes investigated, except for the PCS-12 score which influenced adult vaccinations. Holm et al [36] also found that poor health led most frequently to eventual vaccination.

Even tough we provide perceptive examinations of access and delivery of preventive care, our findings must be interpreted within the context of the study's limitations. The data were cross-sectional, patient-based and self-reported. Self reports, compared to other major data sources, such as medical records, may result in overestimates or underestimates of quality of preventive care. Stange et al [70], who compared medical records review and patient questionnaire methods to the gold standard of direct observation of the outpatient visit, showed that medical record review is preferable to patient questionnaire only with respect to the variables for which there are limitations in patient understanding or knowledge. Patient reporting is a more valid measure for other areas of service delivery, such as screening and counseling on health habits items, and reflect high sensitivity toward certain physical examination and cancer screening items that would be overt and memorable to a patient, such as Pap smear and breast and pelvic examinations; therefore, we do not think that our method of measuring the delivery of clinical preventive services may represent a substantial problem for the interpretation of our results.

The Rand Quality Indicators on health habits are recommended as a one time question and it may be that some patients would satisfy the quality indicator but may not remember that their PCP asked about them many years ago. In addition we do not have data on drinking problem or drug abuse and individuals may better remember services delivered for an actual problem rather than for prevention. Moreover, it should also be pointed out that if patients were only seen one time for an urgent issue it would be unlikely that they received these services.

Our results have significant implications for health care policymakers, since the indicators we used demonstrated to be a useful tool for monitoring access to clinical preventive services, assessing effectiveness of statewide preventive health program, improve quality and reduce barriers to access to preventive health care through the implementation of future interventions in this population. 


\section{Conclusion}

For most Southern Italians, the healthcare system while universal and free is not doing a good job delivering vital clinical preventive services.

\section{Additional material}

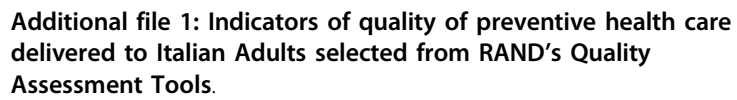

\section{List of abbreviations}

PCP: primary care physician; SES: socioeconomic status; BRFSS: Behavioral Risk Factor Surveillance System.

\section{Acknowledgements}

The authors wish to thank all of the men and women who agreed to participate in this study.

\section{Authors' contributions}

BM collected the data, and contributed to the data analysis and interpretation and wrote the first draft of the article. PR, AB and CGAN contributed to conception and design of the study, collected the data, and contributed to the data analysis and interpretation. MP designed the study, was responsible for the data analysis and interpretation, have been involved in revising the manuscript and have given final approval of the version to be published.

All authors read and approved the final manuscript.

\section{Competing interests}

The authors declare that they have no competing interests.

Received: 11 September 2009 Accepted: 18 June 2010 Published: 18 June 2010

\section{References}

1. Crabtree BF, Miller WL, Tallia AF, Cohen DJ, DiCicco-Bloom B, Mcllvain HE, Aita VA, Scott JG, Gregory PB, Stange KC, McDaniel RR Jr: Delivery of clinical preventive services in family medicine offices. Ann Fam Med 2005, 3:430-435

2. McGlynn EA, Asch SM, Adams J, Keesey J, Hicks J, DeCristofaro A, Kerr EA The quality of health care delivered to adults in the United States. N Engl J Med 2003, 348:2635-2645.

3. Asch SM, Kerr EA, Keesey J, Adams JL, Setodji CM, Malik S, McGlynn EA: Who is at greatest risk for receiving poor-quality health care? $N$ Engl J Med 2006, 354:1147-1156.

4. Shenson D, Adams M, Bolen J: Delivery of preventive services to adults aged 50-64: monitoring performance using a composite measure, 19972004. J Gen Intern Med 2008, 23:733-740.

5. Shenson D, Bolen J, Adams M: Receipt of preventive services by elders based on composite measures, 1997-2004. Am J Prev Med 2007, 32:11-18.

6. Shenson D, Benson W, Harris AC: Expanding the delivery of clinical preventive services through community collaboration: the SPARC model Prev Chronic Dis 2008, 5:A20.

7. Giordano L, Giorgi D, Piccini P, Ventura L, Stefanini V, Senore C, Paci E, Segnan N: Time trends of process and impact indicators in Italian breast screening programmes-1996-2005. Epidemiol Prev 2008, 32:23-36.

8. Ronco G, Giubilato P, Naldoni C, Zorzi M, Anghinoni E, Scalisi A, Dalla Palma P, Zanier L, Barca A, Angeloni C, Prandini S, Maglietta R, Mancini E, Pizzuti R, lossa A, Segnan N, Zappa M: Extension of organised cervical cancer screening programmes in Italy and their process indicators. Epidemiol Prev 2008, 32:37-54.

9. Zorzi M, Falcini F, Fedato C, Grazzini G, de' Bianchi PS, Senore C, Vettorazzi M, Visioli C, Zappa M: Screening for colorectal cancer in Italy: 2006 survey. Epidemiol Prev 2008, 32:55-68.
10. Holmes JS, Arispe IE, Moy E: Heart disease and prevention race and age differences in heart disease prevention, treatment, and mortality. Med Care 2005, 43(suppl 3):133-41.

11. Ajani UA, Ford ES, Okoro CA, Strine TW, Giles WH, Mokdad AH: Low prevalence of influenza vaccination among people with cardiovascular disease-BRFSS. Am J Prev Med 2005, 29:31-35

12. Fenton JJ, Cai Y, Weiss NS, Elmore JG, Pardee RE, Reid RJ, Baldwin LM: Delivery of cancer screening: how important is the preventive health examination? Arch Intern Med 2007, 167:580-585.

13. Ballard DJ, Nicewander DA, Qin H, Fullerton C, Winter FD, Couch CE: Improving delivery of clinical preventive services a multi-year journey. Am J Prev Med 2007, 33:492-497.

14. Ewing GB, Selassie AW, Lopez CH, McCutcheon EP: Self-report of delivery of clinical preventive services by U.S. physicians comparing specialty, gender, age, setting of practice, and area of practice. Am J Prev Med 1999, 17:62-72.

15. Stange KC, Flocke SA, Goodwin MA, Kelly RB, Zyzanski SJ: Direct observation of rates of preventive service delivery in community family practice. Prev Med 2000, 31:167-176.

16. Weyer SM, Konrad N, Esola D, Goodwin MA, Stange KC, Flocke SA: Features of medical records in community practices and their association with preventive service delivery. Med Care 2005, 43:28-33.

17. The World Health Organization: Health topics: chronic diseases. [http:// www.who.int/topics/chronic_diseases/en/]

18. Behavioral Risk Factor Surveillance System Questionnaire 2007. [http:// www.cdc.gov/brfss/questionnaires/pdf-ques/2007brfss.pdf].

19. Quick Stats General Information on Alcohol Use and Health. [http://www. cdc.gov/Alcohol/quickstats/general_info.htm].

20. Ware J Jr, Kosinski M, Keller SD: A 12-Item Short-Form Health Survey: construction of scales and preliminary tests of reliability and validity. Med Care 1996, 34:220-233.

21. Hays RD, Morales LS: The RAND-36 measure of health-related quality of life. Ann Med 2001, 33:350-357.

22. Apolone G, Mosconi P, Quattrociocchi L, Gianicolo EAL, Groth N, Ware JE: Questionario sullo stato di salute Sf-12, Versione Italiana 2005. [http://crc. marionegri.it/qdv/downloads/SF12\%20Manuale.pdf].

23. Stata Corporation: Stata Reference Manual Release 10 College Station TX 2007

24. U.S Preventive Services Task Force: Counseling and interventions to prevent tobacco use and tobacco-caused disease in adults and pregnant women: U.S. Preventive Services Task Force reaffirmation recommendation statement. Ann Intern Med 2009, 150:551-555.

25. U.S. Preventive Services Task Force: Screening for high blood pressure: U. S. Preventive Services Task Force reaffirmation recommendation statement. Ann Intern Med 2007, 147:783-786.

26. U.S. Preventive Services Task Force: Behavioral counseling to prevent sexually transmitted infections: U.S. Preventive Services Task Force recommendation statement. Ann Intern Med 2008, 149:491-496.

27. Humphrey LL, Helfand M, Chan BK, Woolf SH: Breast cancer screening: a summary of the evidence for the U.S. Preventive Services Task Force. Ann Intern Med 2002, 137:347-360.

28. Knutson D, Steiner E: Screening for breast cancer: current recommendations and future directions. Am Fam Physician 2007, 75:1660-1666.

29. Elmore JG, Armstrong K, Lehman CD, Fletcher SW: Screening for breast cancer. JAMA 2005, 293:1245-1256.

30. Coughlin SS, Breslau ES, Thompson T, Benard VB: Physician recommendation for papanicolaou testing among U.S. women, 2000. Cancer Epidemiol Biomarkers Prev 2005, 14:1143-1148.

31. Insinga RP, Glass AG, Rush BB: Pap screening in a U.S. health plan. Cancer Epidemiol Biomarkers Prev 2004, 13:355-360.

32. Solomon D, Breen N, McNeel T: Cervical cancer screening rates in the United States and the potential impact of implementation of screening guidelines. CA Cancer J Clin 2007, 57:105-111.

33. U.S. Preventive Services Task Force: Screening for colorectal cancer: U.S. Preventive Services Task Force recommendation. Ann Intern Med 2008, 149:627-637.

34. Whitlock EP, Lin JS, Liles E, Beil TL, Fu R: Screening for colorectal cancer: a targeted, updated systematic review for the U.S. Preventive Services Task Force. Ann Intern Med 2008, 149:638-658. 
35. Zauber AG, Lansdorp-Vogelaar I, Knudsen AB, Wilschut J, van Ballegooijen M, Kuntz KM: Evaluating test strategies for colorectal cancer screening: a decision analysis for the U.S. Preventive Services Task Force. Ann Intern Med 2008, 149:659-669.

36. Holm MV, Szucs TD, Fara GM: Developments in influenza vaccination coverage in Italy over five seasons (2001-2006). Ann lg 2007, 19:405-415.

37. Nelson DE, Bland S, Powell-Griner E, Klein R, Wells HE, Hogelin G, Marks JS: State trends in health risk factors and receipt of clinical preventive services among US adults during the 1990s. JAMA 2002, 287:2659-2667.

38. Smith RA, Cokkinides V, Eyre HJ: Cancer Screening in the United States, 2007: A Review of Current Guidelines, Practices, and Prospects. CA Cancer J Clin 2007, 57:90-104

39. Smith RA, Cokkinides V, Brawley OW: Cancer screening in the United States, 2009: A review of current American Cancer Society guidelines and issues in cancer screening. CA Cancer J Clin 2009, 59:27-41.

40. Aspy CB, Enright M, Halstead L, Mold JW: Improving mammography screening using best practices and practice enhancement assistants: an Oklahoma Physicians Resource/Research Network (OKPRN) study. J Am Board Fam Med 2008, 21:326-333.

41. Silverstein MD, Ogola G, Mercer Q, Fong J, Devol E, Couch CE, Ballard DJ: Impact of clinical preventive services in the ambulatory setting. Proc (Bayl Univ Med Cent) 2008, 21:227-235

42. Kilmer G, Roberts H, Hughes E, Li Y, Valluru B, Fan A, Giles W, Mokdad A Jiles R, Centers for Disease Control and Prevention (CDC): Surveillance of certain health behaviors and conditions among states and selected local areas-Behavioral Risk Factor Surveillance System (BRFSS), United States, 2006. MMWR Surveill Summ 2008, 57:1-188.

43. Asch SM, Sloss EM, Hogan C, Brook RH, Kravitz RL: Measuring underuse of necessary care among elderly Medicare beneficiaries using inpatient and outpatient claims. JAMA 2000, 284:2325-2333.

44. Koroukian SM, Xu F, Dor A, Cooper GS: Colorectal cancer screening in the elderly population: disparities by dual Medicare-Medicaid enrollment status. Health Serv Res 2006, 41:2136-2154

45. Pham HH, Schrag D, Hargraves JL, Bach PB: Delivery of preventive services to older adults by primary care physicians. JAMA 2005, 294:473-481.

46. Fiscella $K$, Holt K, Meldrum S, Franks P: Disparities in preventive procedures: comparisons of self-report and Medicare claims data. BMC Health Serv Res 2006, 6:122-129.

47. Fiscella K, Holt K: Impact of primary care patient visits on racial and ethnic disparities in preventive care in the United States. J Am Board Fam Med 2007, 20:587-597.

48. Okoro CA, Strine TW, Young SL, Balluz LS, Mokdad AH: Access to health care among older adults and receipt of preventive services. Results from the Behavioral Risk Factor Surveillance System, 2002. Prev Med 2005, 40:337-343.

49. Si D, Bailie RS, Dowden M, O'Donoghue L, Connors C, Robinson GW, Cunningham J, Condon JR, Weeramanthri TS: Delivery of preventive health services to Indigenous adults: response to a systems-oriented primary care quality improvement intervention. MJA 2007, 187:453-457.

50. Blank PR, Schwenkglenks M, Szucs TD: Influenza vaccination coverage rates in five European countries during season 2006/07 and trends over six consecutive seasons. BMC Public Health 2008, 8:272-282.

51. Pavia M, Foresta MR, Carbone $V$, Angelillo IF: Influenza and pneumococcal immunization in the elderly: knowledge, attitudes, and practices among general practitioners in Italy. Public Health 2003, 117:202-207.

52. D'Amico EJ, Paddock SM, Burnam A, Kung FY: Identification of and guidance for problem drinking by general medical providers: results from a national survey. Med Care 2005, 43:229-236.

53. Solberg LI, Asche SE, Boyle RG, Boucher JL, Pronk NP: Frequency of Physician-Directed Assistance for Smoking Cessation in Patients Receiving Cessation Medications. Arch Intern Med 2005, 165:656-660.

54. Cornuz J, Ghali WA, Di Carlantonio D, Pecoud A, Paccaud F: Physicians' attitudes towards prevention: importance of intervention-specific barriers and physicians' health habits. Fam Pract 2000, 17:535-540.

55. Morales LS, Rogowski J, Freedman VA, Wickstrom SL, Adams JL, Escarce J: Sociodemographic differences in use of preventive services by women enrolled in Medicare + Choice plans. Prev Med 2004, 39:738-745.

56. Qi V, Phillips SP, Hopman WM: Determinants of a healthy lifestyle and use of preventive screening in Canada. BMC Public Health 2006, 6:275-282.
57. Appel A, Everhart R, Mehler PS, MacKenzie TD: Lack of ethnic disparities in adult immunization rates among underserved older patients in an urban public health system. Med Care 2006, 44:1054-1058

58. Ko CW, Kreuter W, Baldwin LM: Persistent demographic differences in colorectal cancer screening utilization despite Medicare reimbursement. BMC Gastroenterol 2005, 5:10-17.

59. Mukamal KJ: Impact of race and ethnicity on counseling for alcohol consumption: a population-based, cross-sectional survey. Alcohol Clin Exp Res 2007, 31:452-457.

60. Rizza P, Bianco A, Pavia M, Angelillo IF: Preventable hospitalization and access to primary health care in an area of Southern Italy. BMC Health Serv Res 2007, 7:134-141.

61. Pileggi C, Carbone V, Pavia M, Angelillo IF: Patients' perceptions and related behaviours on role of primary care physician in Italy. Eur J Public Health 2004, 14:258-260.

62. Bianco A, Pileggi C, Angelillo IF: Non-urgent visits to a hospital emergency department in Italy. Public Health 2003, 117:250-255.

63. La prevenzione dei tumori femminili in Italia: il ricorso a pap test e mammografia. Anni 2004-2005. [http://www.istat.it/salastampa/comunicati/ non calendario/20061204_00/testointegrale.pdf].

64. Sambamoorthi U, McAlpine DD: Racial, ethnic, socioeconomic, and access disparities in the use of preventive services among women. Prev Med 2003, 37:475-484.

65. Scott TL, Gazmararian JA, Williams MV, Baker DW: Health literacy and preventive health care use among Medicare enrollees in a managed care organization. Med Care 2002, 40:395-404

66. Morales LS, Rogowski J, Freedman VA, Wickstrom SL, Adams JL, Escarce JJ: Use of preventive services by men enrolled in Medicare + Choice plans. Am J Public Health 2004, 94:796-802.

67. Ampt AJ, Amoroso C, Harris MF, McKenzie SH, Rose VK, Taggart JR: Attitudes, norms and controls influencing lifestyle risk factor management in general practice. BMC Fam Pract 2009, 10:59-66.

68. Condizioni di salute, fattori di rischio e ricorso ai servizi sanitari. Anno 2005. [http://www.istat.it/salastampa/comunicati/non_calendario/ 20070302_00/testointegrale.pdf]

69. Wallace AE, Weeks WB, Wang S, Lee AF, Kazis LE: Rural and urban disparities in health-related quality of life among veterans with psychiatric disorders. Psychiatr Serv 2006, 57:851-856.

70. Stange KC, Zyzanski SJ, Smith TF, Kelly R, Langa DM, Flocke SA, Jaén CR: How valid are medical records and patient questionnaires for physician profiling and health services research? A comparison with direct observation of patient visits. medical care. Med Care 1998, 36:851-867.

\section{Pre-publication history}

The pre-publication history for this paper can be accessed here: http://www.biomedcentral.com/1471-2458/10/350/prepub

doi:10.1186/1471-2458-10-350

Cite this article as: Manuti et al:: The quality of preventive health care delivered to adults: results from a cross-sectional study in Southern Italy. BMC Public Health 2010 10:350

\section{Submit your next manuscript to BioMed Central and take full advantage of:}

- Convenient online submission

- Thorough peer review

- No space constraints or color figure charges

- Immediate publication on acceptance

- Inclusion in PubMed, CAS, Scopus and Google Scholar

- Research which is freely available for redistribution

Submit your manuscript at www.biomedcentral.com/submit
Biomed Central 